\title{
Close Association Between Non-Alcoholic Fatty Liver Disease and Ossification of the Posterior Longitudinal Ligament of the Spine
}

\section{Tsutomu Endo}

Hokkaido University Graduate School of Medicine

\section{Yoshinao Koike}

Hokkaido University Graduate School of Medicine

Hideaki Miyoshi

Hokkaido University

\section{Yuichiro Hisada}

Hokkaido University Graduate School of Medicine

\section{Ryo Fujita}

Hokkaido University Graduate School of Medicine

\section{Ryota Suzuki}

Hokkaido University Graduate School of Medicine

\section{Masaru Tanaka}

Hakodate Central General Hospital

\section{Takeru Tsujimoto}

Hakodate Central General Hospital

\section{Yukitoshi Shimamura}

Hakodate Central General Hospital

\section{Yuichi Hasegawa}

Hakodate Central General Hospital

\section{Masahiro Kanayama}

Hakodate Central General Hospital

\section{Tomoyuki Hashimoto}

Hakodate Central General Hospital

\section{Fumihiro Oha}

Hakodate Central General Hospital

\section{Naoki Noro}

Hakodate Central General Hospital

\section{Kiyofumi Komano}

Hakodate Central General Hospital

\section{Misaki Ishii}


Hakodate Central General Hospital

\section{Yoichi M. Ito}

Hokkaido University Hospital

\section{Norimasa Iwasaki}

Hokkaido University Graduate School of Medicine

Masahiko Takahata ( $\nabla$ takamasa@med.hokudai.ac.jp)

Hokkaido University Graduate School of Medicine

\section{Research Article}

Keywords: posterior longitudinal ligament (OPLL), etiology, liver-to-spleen, ossification index

Posted Date: July 29th, 2021

DOl: https://doi.org/10.21203/rs.3.rs-746962/v1

License: (c) (i) This work is licensed under a Creative Commons Attribution 4.0 International License. Read Full License 


\section{Abstract}

Ossification of the posterior longitudinal ligament (OPLL) of the spine is a disease of unknown etiology occurring frequently in individuals with metabolic disturbances. Obesity has been suggested as a potential risk factor for the severity of OPLL. We aimed to investigate whether non-alcoholic fatty liver disease (NAFLD) is associated with OPLL severity. We assessed the severity of NAFLD by a liver-to-spleen (L/S) ratio on computed tomography (CT) scans of 85 symptomatic OPLL patients at a single institution in Japan. We also assessed the severity of OPLL by CT reconstruction sagittal and axial images. The prevalence of NAFLD in middle-aged patients (age $<70$ years, $n=50$ ) was $80.3 \%$, which was $2.5-8$ times higher than that in the general Japanese population (9-30\%). The ossification index of the spinal ligaments increased in proportion to the severity of fatty liver. The L/S ratio was revealed as a significant risk factor associated with the total ossification index (standardized $\beta$ : $-0.40,95 \%$ confidence interval: -54.34 to -4.22$)$. This study suggests the potential contribution of NAFLD to the progression of OPLL. The close association between NAFLD and OPLL demonstrated in this study warrants further study to elucidate the causal nature of this relationship.

\section{Introduction}

Heterotopic ossification of the posterior longitudinal ligament (OPLL) is a disease of unknown etiology that most frequently affects the cervical spine, causing myelopathy.[1-4] However, recent studies have demonstrated that there is a clinically important patient subgroup that develops OPLL in other regions, including the thoracic and lumbar spine.[5-7] Epidemiological studies have revealed that patients with thoracic OPLL have a strong tendency toward an early onset of symptoms and a high prevalence of morbid obesity, as well as co-existing ossified lesions of spinal ligaments over the entire spine.[8, 9] This prompted us to further investigate the association between obesity-related diseases and OPLL.

Non-alcoholic fatty liver disease (NAFLD) is very common among individuals with obesity, and it is attributable to over-nutrition, a sedentary lifestyle, sarcopenia, and genetic background. $[10,11]$ NAFLD is also closely related to metabolic disturbances. Therefore, there is an on-going international effort to rename NAFLD to metabolic dysfunction-associated fatty liver disease (MAFLD).[12] MAFLD is diagnosed by evidence of hepatic steatosis as well as concomitant diabetes mellitus type 2 , being overweight, or having metabolic disturbances, all of which are frequently observed in patients with OPLL. [10-16] Despite the shared features between NAFLD and OPLL, no previous studies have explored the association between them. This may be due to inadequate awareness of the presence of NAFLD by physicians, as well as the patients themselves, as most patients with NAFLD remain asymptomatic and liver function tests mostly show normal results, with mild elevations in aminotransferases.[17-19] Thus, it is of great interest to determine whether patients with OPLL have a high prevalence of NAFLD, as well as whether there is a link between NAFLD and OPLL.

At present, there is no therapeutic approach based on the progression of OPLL, and surgery is the only treatment option used to relieve myelopathy. In order to develop novel therapeutic strategies against 
OPLL, it is necessary to explore the underlying etiology associated with severe OPLL. Therefore, we aimed to determine the prevalence of NAFLD in symptomatic patients with OPLL and to assess whether the severity of fatty liver is associated with the severity of OPLL.

\section{Methods}

\section{Study design}

A retrospective cross-sectional study was conducted. All patients were included between June 2019 and May 2020. The study was conducted in accordance with the Declaration of Helsinki (1964) and was approved by the ethics committee of the Hakodate Central Hospital and Hokkaido University Hospital. Written informed consent was obtained from all participants.

\section{Patients}

All patients with OPLL were diagnosed and followed up by a spine surgeon or radiologist based on clinical symptoms and computed tomography (CT) images at the time of diagnosis. Of the 94 patients who regularly visited a single institution, 6 patients who had not undergone CT scans including liver, spleen, and entire spine were excluded. Three patients who regularly consumed alcohol (30 g/day or more for men and $20 \mathrm{~g} /$ day or more for women) and were at risk of developing alcoholic liver disease were excluded.[18, 19] Finally, a total of 85 patients (35 males and 50 females) were included in this study.

\section{Grouping of patients with OPLL according to their age and OPLL type}

In the evaluation of the association between fatty liver and OPLL, patients were divided into middle-aged (age $<70$ years, $n=50$ ) and elderly groups (age $\geq 70$ years, $n=35$ ). This grouping was performed because fat deposits in the hepatocytes tend to disappear as liver fibrosis progresses from the eighth decade of life onward (> 70 years),[20-22] and OPLL is presumed to develop in the sixth (50-60 years old) and seventh (60-70 years old) decade of life, or earlier.[23-25]

We also divided patients according to OPLL type: patients with OPLL only in the cervical spine were classified into the localized-OPLL group, and those with OPLL in the thoracolumbar spine, with or without cervical spine involvement, were classified into the diffuse-OPLL group. This classification was based on our previous study showing that patients with myelopathy caused by thoracic OPLL have distinct features, such as severe obesity, early symptom onset, and diffuse ossification of the spinal ligaments.[8, 9]

\section{Demographics, comorbidities, and OPLL distribution}

Demographic data were obtained from all participants. Their current body mass index (BMI), comorbidities (diabetes, hypertension, hyperlipidemia, heart disease, kidney disease, hyperuricemia, and 
cancer), and drinking habits were assessed. The distribution of OPLL was assessed by sagittal reconstruction computed tomography (CT) images of the entire spine.

\section{Image acquisition}

Non-contrast CT scans involving the liver, spleen, and entire spine were obtained for each patient using a CT-Aquilion ONE ${ }^{\mathrm{TM}}$ / GENESIS Edition system (Canon Medical Systems Corporation, Tochigi, Japan). To reduce motion artifacts, three consecutive scans were performed while the patient held their breath.

BMI criteria by World Health Organization (WHO) and the Japan Society for the Study of Obesity (JASSO) guidelines

For adults, the current WHO guidelines define BMI: $18.5-24.9 \mathrm{~kg} / \mathrm{m}^{2}$ as the normal range, $\mathrm{BMI} \geq 25$ $\mathrm{kg} / \mathrm{m}^{2}$ as overweight, $\mathrm{BMI} \geq 30 \mathrm{~kg} / \mathrm{m}^{2}$ as obese, and $\mathrm{BMI} \geq 40 \mathrm{~kg} / \mathrm{m}^{2}$ as highly obese.[26] In 2002, the WHO Expert Committee proposed to lower the BMI cut-off point, which would trigger public health action among Asian people, categorizing BMI: $18.5-22.9 \mathrm{~kg} / \mathrm{m}^{2}$ as the normal range, BMl: $23-27.4 \mathrm{~kg} / \mathrm{m}^{2}$ as overweight, and BMI $\geq 27.5 \mathrm{~kg} / \mathrm{m}^{2}$ as obese.[26, 27] The JASSO guidelines set BMI cut-off points of 25 $\mathrm{kg} / \mathrm{m}^{2}$ as obese and $35 \mathrm{~kg} / \mathrm{m}^{2}$ as highly obese.[28] JASSO defines BMI: $18.5-24.9 \mathrm{~kg} / \mathrm{m}^{2}$ as the normal range, BMI: $25.0-29.9 \mathrm{~kg} / \mathrm{m}^{2}$ as obese class I, BMI: $30.0-34.9 \mathrm{~kg} / \mathrm{m}^{2}$ as obese class II, BMI: $35.0-39.9$ $\mathrm{kg} / \mathrm{m}^{2}$ as obese class III, and BMI $\geq 40.0 \mathrm{~kg} / \mathrm{m}^{2}$ as obese class IV.

\section{Evaluation of liver fat}

Liver fat measurements were performed independently by two radiology technologists (NN and KK) using Ziostation2 imaging software (Ziosoft, Tokyo, Japan), and the mean value was adopted. Following the guidelines of the Japanese Society of Gastroenterology,[29, 30] the attenuation values (Hounsfield units; $\mathrm{HU}$ ) of the liver and spleen were measured using regions of interest (ROIs) with an area of 400 $\mathrm{mm}^{2}$. Two ROls in the right lobe of the liver, two in the left lobe, and two in the spleen were used as the largest possible areas. Care was taken to exclude hepatic vessels and artifacts, and all measurements were obtained in areas with uniform parenchymal attenuation. HU values measured in each segment of the liver and spleen were averaged. The liver-to-spleen $\mathrm{HU}$ ratio (L/S ratio) was calculated as the mean attenuation value of the liver and spleen. In this study, an L/S ratio $\leq 1.0$ on CT indicated severe fatty liver, $1.0<\mathrm{L} / \mathrm{S}$ ratio $<1.2$ indicated mild fatty liver, and an L/S ratio $\geq 1.2$ indicated non-fatty liver. The percentage of estimated intrahepatic fat deposition was based on the cut-off values of the guidelines of The Japanese Society of Gastroenterology: L/S ratio $0.9: \geq 60 \%$, L/S ratio $1.01: 30-60 \%$, L/S ratio 1.12 : $\leq 30 \%$, L/S ratio 1.2: no fat deposition.[29]

\section{Liver fibrosis index based on laboratory tests and anthropometric parameters}

The fibrosis index based on four factors (FIB-4) was calculated using the following equation: FIB-4 = age (years) $\times$ aspartate aminotransferase (AST; U/L) / [platelet count $\left(10^{9} / \mathrm{L}\right) \times \sqrt{ }$ alanine aminotransferase (ALT; U/L)].[31] Patients who scored $<1.3$ and $>2.67$ on the FIB-4 index are considered to be at low and 
high risks of advanced fibrosis, respectively.[32,33] With increasing age, the false-positive rate of liver fibrosis increases, leading to a decrease in the ability to diagnose based on the FIB-4 index.[33] We referred to the recently proposed cut-off points of the FIB-4 index appropriate for each age group in the Japanese population; a low cut-off point and a high cut-off point, respectively: 1.05 and 1.21 for $\leq 49$ years, 1.24 and 1.96 for $50-59$ years, 1.88 and 2.67 for $60-69$ years, and 1.95 and 2.67 for $\geq 70$ years. [34] The proportion of patients whose scores were above or below the cut-off point in this study was evaluated for each age group and then combined.

\section{Severity of spinal ligament ossification}

The distribution of spinal ligament ossification (i.e., cervical, thoracic, and/or lumbar), including OPLL, ossification of the anterior longitudinal ligament (OALL), ossification of the ligamentum flavum (OLF), and ossification of the supra/interspinous ligaments (OSIL), was evaluated using sagittal reconstruction CT images of the entire spine. To determine the severity of spinal ligament ossification, the OPLL-index, OALL-index, OLF-index, OSIL-index, and total ossification index (defined as the sum of the presence or absence of ossification at each vertebral and intervertebral level) were calculated according to a previously described method. $[5,9]$ The analysis was performed independently by three board-certified spine surgeons ( $T E, M T$, and $\mathrm{YH}$ ). Before reviewing the images, all readers interpreted the same images for 20 patients and an interobserver agreement was determined. The intraclass correlation coefficient (ICC) among the three observers was 0.96 , and the $95 \%$ confidence interval (Cl) was $0.92-0.98$, indicating an extremely high interobserver agreement.

\section{Statistical analysis}

Data were analyzed using BellCurve for Excel software (version 3.10; Social Survey Research Information Co., Ltd., Tokyo, Japan). Statistical significance was set at $\mathrm{P}<0.05$. Normality of data was tested using the Shapiro-Wilk test. The differences in continuous variables between the two groups were evaluated with the Student's t-test (for normally distributed data) or the Mann-Whitney U-test (for non-normally distributed data). Results are presented as mean value \pm standard deviation for parametric variables (normally distributed data) or median (minimum, maximum) for non-parametric variables (non-normally distributed data). The difference in proportions between the two groups were evaluated with Fisher's exact test. Three-group comparisons were evaluated using the Kruskal-Wallis test. The relationship between the independent factors and the severity of spinal ligamentous ossification was analyzed by multiple regression analysis. The ICC was analyzed using a two-way mixed-effect model.

\section{Results}

\section{Prevalence of fatty liver in middle-aged patients with OPLL and the distinct clinical features of patients with OPLL with severe fatty liver}

Most patients with severe myelopathy had a history of spinal surgery. There were no patients with acute viral hepatitis, autoimmune hepatitis, primary biliary cirrhosis, cholelithiasis, or obstructive jaundice. None of the patients were using medications that cause hepatic steatosis, such as prednisolone or 
methotrexate. There were no patients with low nutritional status, including patients with gastrointestinal diseases such as inflammatory bowel disease, or cancer patients who had difficulty eating. The prevalence of fatty liver was $80.3 \%$ among all middle-aged patients with OPLL. Of the 50 middle-aged patients with OPLL, $68.1 \%$ had obesity $\left(>27.5 \mathrm{~kg} / \mathrm{m}^{2}\right)$ according to the WHO Asian BMI criteria.[26,27] The prevalence of fatty liver in patients with obesity was $93.3 \%$, which was significantly greater than that in patients without obesity $(64.2 \%)(P=0.013)$.

Differences in the clinical characteristics of middle-aged patients with OPLL in the non-fatty liver, mild fatty liver, and severe fatty liver groups are shown in Table 1. Compared to those in the non-fatty liver group, patients in the severe fatty liver group had a significantly younger symptom onset age $(P=0.013)$ and significantly higher current $B M I$ value $(P=0.023)$. There was also a tendency, albeit insignificant, toward a younger symptom onset age and higher current BMI value in the mild fatty liver group than in the non-fatty liver group. The proportions of comorbidities were similar among the three groups; however, the prevalence of hypertension, hyperlipidemia, and diabetes mellitus was higher in the three groups than in the general Japanese population.[35].

\section{Higher prevalence of fatty liver in diffuse-OPLL than in the localized-OPLL group among middle-aged patients with OPLL}

Since the proportion of patients with diffuse-OPLL was much higher in the fatty liver group than in the non-fatty liver group (Table 1), we compared the degree of liver fat and liver fibrosis between the localized-OPLL and diffuse-OPLL groups (Figure 1 and Table 2). Although there were no statistically significant differences in the L/S ratio between the localized-OPLL and diffuse-OPLL groups, the proportion of patients with fatty liver (the L/S ratio $<1.2$ ) was significantly higher in the diffuse-OPLL group than in the localized-OPLL group $(P=0.004)$. The FIB-4 index and the proportion of patients with low and high risks of liver fibrosis were not statistically significantly different between the localized-OPLL and diffuse-OPLL groups. Regarding background variables, the proportions of female patients and patients with diabetes mellitus were significantly higher in the diffuse-OPLL group than in the localizedOPLL group. The proportions of patients with $\mathrm{BMI}>25 \mathrm{~kg} / \mathrm{m}^{2}$ and $\mathrm{BMI}>27.5 \mathrm{~kg} / \mathrm{m}^{2}$ were comparable between the two groups. The proportions of patients with $\mathrm{BMI}>30 \mathrm{~kg} / \mathrm{m}^{2}$ and $\mathrm{BMI}>35 \mathrm{~kg} / \mathrm{m}^{2}$ were higher in the diffuse-OPLL group than in the localized-OPLL group, but the difference was not statistically significant.

\section{Association between fatty liver and heterotopic spinal ligament ossification among middle-aged patients with OPLL}

The modified ossification index was used to compare the severity of spinal ligament ossification among the non-fatty, mild fatty, and severe fatty liver groups (Figure 2). The OPLL index in the thoracic spine (TOPLL index), OLF index in the thoracic spine (T-OLF index), and the sum of all ossification indices were significantly higher in the severe fatty liver group than in the non-fatty liver group. The T-OPLL index was 
also significantly higher in the mild fatty liver group than in the non-fatty liver group. Notably, the sum of all ossification indices increased in proportion to the severity of fatty liver.

In a single regression analysis to examine factors associated with the sum of all ossification indices, the $\mathrm{L} / \mathrm{S}$ ratio was identified as the sole risk factor $(\mathrm{P}=0.008)$. Multiple regression analysis using the FIB-4 index and the L/S ratio as well as the previously reported risk factors such as age of symptom onset, BMI, and diabetes mellitus as independent variables revealed that the L/S ratio was associated with the sum of all ossification indices $(P=0.023)$ (Table 3$)$ [8,9,13-15].

\section{Association between OPLL and liver fibrosis in elderly patients with OPLL}

We analyzed the L/S ratio and the FIB-4 index to evaluate whether elderly patients in the diffuse-OPLL group had a higher chance of developing liver fibrosis due to fatty liver in middle age, compared with those in the localized-OPLL group. The clinical characteristics of the elderly patients with OPLL are shown in Table 4. There were no significant differences in the current age and prevalence of comorbidities between the two groups. The overall prevalence of fatty liver was $42.8 \%$ among elderly patients with OPLL, with no statistically significant difference in the L/S ratio between the two groups (Table 5). The proportions of patients with the FIB-4 index below the low cut-off point $(<1.95)$ and above the high cut-off point (>2.67) in all elderly patients with OPLL were $57.1 \%$ and $11.4 \%$, respectively. As expected, the diffuse-OPLL group had a significantly higher mean FIB-4 index than the localized-OPLL group $(P=0.048)$ (Table 5). The proportion of patients at a low risk of advanced liver fibrosis in the diffuse-OPLL group was significantly lower than that in the localized-OPLL group $(P=0.027)$. The proportion of patients at a high risk of advanced liver fibrosis in the diffuse-OPLL group was higher than that in the localized-OPLL group, but the difference was not statistically significant (Table 5).

\section{Discussion}

The current study revealed that the prevalence of NAFLD in symptomatic patients with OPLL aged 70 years or younger was surprisingly high at approximately $80 \%$, which was $2.5-8$ times higher than that in the general Japanese population $(9-30 \%)$. [20, 22] The clinical significance of this finding is that most patients with OPLL with identified fatty liver on CT had not been diagnosed with NAFLD, which may be attributable to the unique nature of the disease, as most patients with NAFLD remain asymptomatic, and the liver function tests are mostly normal or show mild elevations in aminotransferases until the liver fibrosis progresses.[17-19] A possible explanation for the high prevalence of NAFLD in symptomatic patients with OPLL is the multiple risk factors for NAFLD, such as obesity, physical inactivity, a sedentary lifestyle, and sarcopenia, which are accompanying symptoms of myelopathy.[8, 9, 13-16]

Our results suggest that fatty liver is a contributing factor in the progression of spinal ligament ossification. This was supported by the negative correlation between the L/S ratio and the severity of ossification in middle-aged patients. Although few studies have investigated the association between fatty liver and heterotopic ossification, recent research on the gene expression profile of human heterotopic ossification samples 
suggests its association with NAFLD.[36] Of particular note is that changes in lifestyle and dietary habits over the past three decades have led to a pandemic of obesity and NAFLD among Asians.[37, 38] Given that OPLL is particularly common in East Asians,[1-4] NAFLD may become an important risk factor for OPLL progression.

Interestingly, Interestingly, the severity and extent of spinal ligament ossification in the entire spine was correlated with the L/S ratio, rather than the BMI. This indicates that central obesity plays an important role in the progression of heterotopic spinal ossification, and that factors other than mechanical stress are involved in the heterotopic ossification process. Possible candidate factors linking central obesity/fatty liver and OPLL comprise hepatokines and adipokines, as their levels are altered by the accumulation of excessive liver and visceral fat. Insulin-like growth factor 1 (IGF-1) is mainly produced in the liver and acts directly on osteoblasts and osteoclasts to promote bone formation and resorption.[3941] Goto et al. reported that IGF-1 induced osteogenic differentiation in ligamental-cultured cells from patients with OPLL, compared to that in non-OPLL control cells.[42] Additionally, adipokines, such as leptin, have both cytokine and hormonal properties, and play central and peripheral roles in bone metabolism.[43, 44] It was previously reported that serum leptin levels are higher in patients with OPLL than in patients without OPLL.[45] Furthermore, the Zucker fatty rat, which has a missense mutation in the leptin receptor gene, is an animal model of OPLL.[46] The fact that Asians are more prone to central obesity, NAFLD, and type 2 diabetes mellitus than Europeans, partly due to body composition differences in fat and muscle, may also contribute to the higher prevalence of OPLL among Asians.[26, 47]

Additionally, the finding that elderly patients with diffuse-OPLL may be at a higher risk of liver fibrosis than those with localized-OPLL supports the idea that fatty liver in middle age contributes to the progression of heterotopic ossification of the spinal ligaments. The fact that OPLL is presumed to develop in patients during their 50s and 60s, or at a younger age, may also support this idea.[23-25] An acceptable interpretation for the decreased prevalence of fatty liver in elderly patients with OPLL is that fatty liver progresses to liver fibrosis with age and is no longer diagnosed as fatty liver. It has been reported that fat deposits in hepatocytes tend to disappear as liver fibrosis progresses in patients aged of $\geq 70$.[20-23] NAFLD is also important as a comorbidity of OPLL because NAFLD and its pathologically more severe form, non-alcoholic steatohepatitis (NASH), can cause cirrhosis and liver cancer.[10, 11] Thus, patients with OPLL with myelopathy can have a significantly impaired quality of life, and their liver condition requires close attention.

This study has several limitations. First, for ethical reasons, we did not perform liver biopsies, which are required to confirm fatty liver or liver fibrosis. $[18,19]$ Therefore, we could not determine the true prevalence of NAFLD, including NAFL and NASH with liver fibrosis, in patients with OPLL. Instead, we evaluated the presence of NASH using the FIB-4 index, which was calculated from standard laboratory tests and age. A FibroScan and/or MR elastography may be useful for diagnosing NASH in future studies. Second, it remains unclear whether NAFLD or NASH is the cause or consequence of heterotopic spinal ligamentous ossification because this study was cross-sectional in nature. Longitudinal or experimental animal model studies are required to reach a conclusion on this topic. Finally, the sample 
size was small and the statistical power was low because of the rarity of patients with OPLL, especially those with diffuse-OPLL (thoracic OPLL has a prevalence of $0.8 \%$ ).[6] Thus, our findings should be validated in multicenter and nationwide studies in the future.

In summary, patients with OPLL had a high prevalence of NAFLD, and the severity of fatty liver was associated with the severity of spinal ligament ossification. Furthermore, elderly patients with diffuseOPLL may be at risk of advanced liver fibrosis, due to fatty liver disease, compared to those with localized-OPLL. The close association between NAFLD and OPLL demonstrated in this study warrants further study to elucidate the causal nature of this relationship.

\section{Declarations}

Acknowledgements: None

Author contributions: MT designed the project and provided overall project management. TE and MT drafted the main manuscript. TE, MT, YK and YH contributed to analysis and interpretation of data. All other authors have contributed to data collection and critically reviewed the manuscript.

Conflicts of interest: The author(s) declare no competing interests.

Data availability: The datasets generated during and/or analyzed during the current study are available from the corresponding author on reasonable request.

\section{References}

1. Yoshimura, N. et al. Prevalence and progression of radiographic ossification of the posterior longitudinal ligament and associated factors in the Japanese population: a 3-year follow-up of the ROAD study. Osteoporos. Int. 25(3), 1089-1098 (2014).

2. Matsunaga, S. \& Sakou, T. Ossification of the posterior longitudinal ligament of the cervical spine: etiology and natural history. Spine (Phila Pa 1976) 37(5), E309-E314 (2012).

3. Choi, B. W., Song, K. J. \& Chang, H. Ossification of the posterior longitudinal ligament: a review of literature. Asian Spine J. 5(4), 267-276 (2011).

4. Yan, L. et al. The pathogenesis of ossification of the posterior longitudinal ligament. Aging Dis. 8(5), 570-582 (2017).

5. Kawaguchi, Y. et al. Ossification of the posterior longitudinal ligament in not only the cervical spine, but also other spinal regions: analysis using multidetector computed tomography of the whole spine. Spine 38(23), E1477-E1482 (2013).

6. Mori, K. et al. Prevalence, distribution, and morphology of thoracic ossification of the posterior longitudinal ligament in Japanese: results of CT-based cross-sectional study. Spine (Phila Pa 1976) 39(5), 394-399 (2014). 
7. Liang, H. et al. Epidemiology of ossification of the spinal ligaments and associated factors in the Chinese population: a cross-sectional study of 2000 consecutive individuals. BMC Musculoskelet. Disord. 20(1), 253 (2019).

8. Endo, T., Takahata, M., Koike, Y. \& Iwasaki, N. Clinical characteristics of patients with thoracic myelopathy caused by ossification of the posterior longitudinal ligament. J. Bone Miner. Metab. 38(1), 63-69 (2020).

9. Endo, T. et al. Association between vitamin A intake and disease severity in early-onset heterotopic ossification of the posterior longitudinal ligament of the spine. Glob. Spine J. $10.1177 / 2192568221989300$ (2021).

10. Sheka, A. C. et al. Nonalcoholic steatohepatitis: a review. JAMA 323(12), 1175-1183 (2020).

11. Diehl, A. M. \& Day, C. Cause, pathogenesis, and treatment of nonalcoholic steatohepatitis. N. Engl. J. Med. 377(21), 2063-2072 (2017).

12. Eslam M. et al. A new definition for metabolic dysfunction-associated fatty liver disease: An international expert consensus statement. J Hepatol. 73(1), 202-209 (2020).

13. Kobashi, G. et al. High body mass index after age 20 and diabetes mellitus are independent risk factors for ossification of the posterior longitudinal ligament of the spine in Japanese subjects: a case-control study in multiple hospitals. Spine (Phila Pa 1976) 29(9), 1006-1010 (2004).

14. Akune, T. et al. Insulin secretory response is positively associated with the extent of ossification of the posterior longitudinal ligament of the spine. J. Bone Joint Surg. Am. 83(10), 1537-1544 (2001).

15. Shingyouchi, Y., Nagahama, A. \& Niida, M. Ligamentous ossification of the cervical spine in the late middle-aged Japanese men. Its relation to body mass index and glucose metabolism. Spine (Phila Pa 1976) 21(21), 2474-2478 (1996).

16. Washio, M. et al. Sleeping habit and other life styles in the prime of life and risk for ossification of the posterior longitudinal ligament of the spine (OPLL): a case-control study in Japan. J. Epidemiol. 14(5), 168-173 (2004).

17. Schindhelm, R. K. et al. Alanine aminotransferase as a marker of non-alcoholic fatty liver disease in relation to type 2 diabetes mellitus and cardiovascular disease. Diabetes Metab. Res. Rev. 22(6), 437443 (2006).

18. Chalasani, N. et al. The diagnosis and management of non-alcoholic fatty liver disease: practice guideline by the American Gastroenterological Association, American Association for the Study of Liver Diseases, and American College of Gastroenterology. Gastroenterology 142(7), 1592-1609 (2012).

19. European Association for the Study of the Liver (EASL); European Association for the Study of Diabetes (EASD); European Association for the Study of Obesity (EASO). EASL-EASD-EASO Clinical Practice Guidelines for the management of non-alcoholic fatty liver disease. J. Hepatol. 64(6), 13881402; 10.1016/j.jhep.2015.11.004 (2016).

20. Eguchi, Y. et al. Prevalence and associated metabolic factors of nonalcoholic fatty liver disease in the general population from 2009 to 2010 in Japan: a multicenter large retrospective study. J. 
Gastroenterol. 47(5), 586-595 (2012).

21. Ishiba, H. et al. The novel cutoff points for the FIB4 index categorized by age increase the diagnostic accuracy in NAFLD: a multi-center study. J. Gastroenterol. 53(11), 1216-1224 (2018).

22. Watanabe, S. et al. Evidence-based clinical practice guidelines for nonalcoholic fatty liver disease/nonalcoholic steatohepatitis. J. Gastroenterol. 50(4), 364-377 (2015).

23. Wu, J. C. et al. Ossification of the posterior longitudinal ligament in the cervical spine: an 11-year comprehensive national epidemiology study. Neurosurg. Focus 30(3), E5 (2011).

24. Katsumi, K. et al. Natural history of the ossification of cervical posterior longitudinal ligament: a three dimensional analysis. Int. Orthop. 42(4), 835-842 (2018).

25. Doi, T. et al. Risk factors for progression of ossification of the posterior longitudinal ligament in asymptomatic subjects. J. Neurosurg. Spine 33(3), 316-322; 10.3171/2020.3.SPINE2082 (2020).

26. WHO Expert Consultation. Appropriate body-mass index for Asian populations and its implications for policy and intervention strategies. Lancet 363(9403), 157-163 (2004).

27. Jih, J. et al. Using appropriate body mass index cut points for overweight and obesity among Asian Americans. Prev. Med. 65, 1-6 (2014).

28. Examination Committee of Criteria for 'Obesity Disease' in Japan, et al. New criteria for 'obesity disease' in Japan. Circ. J. 66(11), 987-992 (2002).

29. Japanese Society of Gastroenterology. Evidence-based Clinical Practice Guidelines for Nonalcoholic Fatty Liver Disease/Nonalcoholic Steatohepatitis.

https://www.jsge.or.jp/files/uploads/NAFLD_NASHGL2_re.pdf (2014). [in Japanese]

30. Iwasaki M. et al. Noninvasive Evaluation of Graft Steatosis in Living Donor Liver Transplantation. Transplantation 78(10), 1501-1505 (2004).

31. Sterling, R. K. et al. Development of a simple noninvasive index to predict significant fibrosis in patients with HIV/HCV coinfection. Hepatology 43(6), 1317-1325 (2006).

32. Kaya E. et al. Simple Noninvasive Scores Are Clinically Useful to Exclude, Not Predict, Advanced Fibrosis: A Study in Turkish Patients with Biopsy-Proven Nonalcoholic Fatty Liver Disease. Gut. Liver 14(4), 486-491 (2020).

33. Shah, A. G. et al. Comparison of noninvasive markers of fibrosis in patients with nonalcoholic fatty liver disease. Clin. Gastroenterol. Hepatol. 7(10), 1104-1112 (2009).

34. Ishiba, H. et al. The novel cutoff points for the FIB4 index categorized by age increase the diagnostic accuracy in NAFLD: a multi-center study. J. Gastroenterol. 53(11), 1216-1224 (2018).

35. Ministry of Health, Labor and Welfare. National health and nutrition survey. https://www.mhlw.go.jp/content/000615344.pdf (2020).

36. Wang, S. et al. Identification of the biomarkers and pathological process of heterotopic ossification: weighted gene co-expression network analysis. Front. Endocrinol. Lausanne 11; 10.3389/fendo.2020.581768 (2020). 
37. Chitturi, S., Wong, V. W. \& Farrell, G. Nonalcoholic fatty liver in Asia: firmly entrenched and rapidly gaining ground. J. Gastroenterol. Hepatol. 26 Suppl 1, 163-172 (2011).

38. Zhou, F. et al. Unexpected rapid increase in the burden of NAFLD in China from 2008 to 2018: a systematic review and meta-analysis. Hepatology 70(4), 1119-1133 (2019).

39. Kasukawa, Y., Miyakoshi, N. \& Mohan, S. The anabolic effects of GH/IGF system on bone. Curr. Pharm. Des. 10(21), 2577-2592 (2004).

40. Ohlsson, C. et al. The role of liver-derived insulin-like growth factor-I. Endocr. Rev. 30(5), 494-535 (2009).

41. Xian, L. et al. Matrix IGF-1 maintains bone mass by activation of mTOR in mesenchymal stem cells. Nat. Med. 18(7), 1095-1101 (2012).

42. Goto, K. et al. Involvement of insulin-like growth factor I in development of ossification of the posterior longitudinal ligament of the spine. Calcif. Tissue Int. 62(2), 158-165 (1998).

43. Zhou, B. O., Yue, R., Murphy, M. M., Peyer, J. G. \& Morrison, S. J. Leptin-receptor-expressing mesenchymal stromal cells represent the main source of bone formed by adult bone marrow. Cell Stem Cell 15(2), 154-168 (2014).

44. Reid, I. R., Baldock, P. A. \& Cornish, J. Effects of leptin on the skeleton. Endocr. Rev. 39(6), 938-959 (2018).

45. Ikeda, Y. et al. Association between serum leptin and bone metabolic markers, and the development of heterotopic ossification of the spinal ligament in female patients with ossification of the posterior longitudinal ligament. Eur. Spine J. 20(9), 1450-1458 (2011).

46. Okano, T. et al. Orthotopic ossification of the spinal ligaments of Zucker fatty rats: a possible animal model for ossification of the human posterior longitudinal ligament. J. Orthop. Res. 15(6), 820-829 (1997).

47. Rattarasarn, C. Dysregulated lipid storage and its relationship with insulin resistance and cardiovascular risk factors in non-obese Asian patients with type 2 diabetes. Adipocyte 7(2), 71-80 (2018).

\section{Tables}

Table 1. Comparison of clinical characteristics and OPLL types among middle-aged patients (age $<70$ years) with non-fatty, mild fatty, and severe fatty liver 


\begin{tabular}{|c|c|c|c|}
\hline & & Fatty liver & \\
\hline & Non-fatty & Mild fatty & Severe fatty \\
\hline & liver & liver & liver \\
\hline & $(n=9)$ & $(n=18)$ & $(n=23)$ \\
\hline \multicolumn{4}{|l|}{ Variable } \\
\hline Current age (years) & $64(50 \otimes 69)$ & $58(34 \llbracket 69)$ & $59(43 \llbracket 69)$ \\
\hline Age of OPLL symptom onset (years) & $58(50 \otimes 69)$ & $54(29 \llbracket 66)$ & $50(41 \llbracket 65)$ \\
\hline Age of onset $<50$ years (\%) & 0 & 33.3 & 47.8 \\
\hline Male (\%) & 44.4 & 38.8 & 31.2 \\
\hline Current BMI (kg/m²) & $25.6(23.5 \rrbracket 31.8)$ & $28.6(23.4 \llbracket 37.2)$ & $31.7(21.0 \rrbracket 39.1)$ \\
\hline Current BMI $\geq 25.0 \mathrm{~kg} / \mathrm{m}^{2}(\%)$ & 57.1 & 88.2 & 90.9 \\
\hline Current BMI $\geq 27.5 \mathrm{~kg} / \mathrm{m}^{2}(\%)$ & 28.1 & 66.6 & 73.9 \\
\hline Current BMI $\geq 30.0 \mathrm{~kg} / \mathrm{m}^{2}(\%)$ & 14.2 & 35.2 & 59.1 \\
\hline Current BMI $\geq 35.0 \mathrm{~kg} / \mathrm{m}^{2}(\%)$ & 0 & 11.7 & 22.7 \\
\hline Platelet $\left(10^{9} / \mathrm{L}\right)$ & $275(148 \rrbracket 274)$ & $229(140 \rrbracket 383)$ & $246(104 \rrbracket 437)$ \\
\hline AST (U/L) & $32.7 \pm 18.7$ & $25.8 \pm 15.6$ & $28.1 \pm 11.1$ \\
\hline $\operatorname{ALT}(\mathrm{U} / \mathrm{L})$ & $38(12 \bigotimes 72)$ & $19(11 \rrbracket 59)$ & $30(13 \llbracket 64)$ \\
\hline AST/ALT & $0.9(0.5 \bigotimes 1.2)$ & $1.1(0.5 \bigotimes 1.7)$ & $0.8(0.6 \rrbracket 1.9)$ \\
\hline \multicolumn{4}{|l|}{ Comorbidity (\%): } \\
\hline Myocardial infarction & 0 & 0 & 4.3 \\
\hline Angina pectoris & 11.1 & 5.5 & 8.7 \\
\hline Hypertension & 55.5 & 38.8 & 69.5 \\
\hline Hyperlipidemia & 33.3 & 50.0 & 34.7 \\
\hline Diabetes mellitus & 11.1 & 44.4 & 43.4 \\
\hline Cancer & 0 & 5.5 & 4.7 \\
\hline Renal disease & 0 & 11.1 & 0 \\
\hline Gout & 0 & 16.6 & 8.6 \\
\hline Drinking alcohol habits (\%) & 22.2 & 27.7 & 17.4 \\
\hline
\end{tabular}


Types of OPLL (\%):

Localized-OPLL

55.5

11.1

17.3

Diffuse-OPLL

11.1

88.9

82.6

Data are shown as mean \pm standard deviation for normally distributed variables and median (minimum-maximum) for non-normally distributed variables, and as the percentage. Patients were divided into three groups according to the liver-to-spleen ratio (L/S ratio) on computed tomography. The non-fatty liver group includes patients with an L/S ratio $\geq 1.2$; the mild fatty liver group includes patients with $1.0<\mathrm{L} / \mathrm{S}$ ratio $<1.2$; and the severe fatty liver group included patients with an L/S ratio $\leq 1.0$.

OPLL, ossification of the posterior longitudinal ligament; BMI, body mass index; L/S liver-to-spleen.

Table 2. Comparison of the severity of fatty liver and liver fibrosis between middle-aged patients with localized-OPLL and diffuse-OPLL 


\begin{tabular}{|c|c|c|c|}
\hline Variable & $\begin{array}{l}\text { Localized-OPLL } \\
(n=11)\end{array}$ & $\begin{array}{l}\text { Diffuse-OPLL } \\
(n=37)\end{array}$ & P-value \\
\hline Current age (years) & $61(50 \otimes 69)$ & $60(34 \llbracket 69)$ & 0.825 \\
\hline Age of OPLL symptom onset (years) & $54(47 \rrbracket 68)$ & $51(29 \llbracket 68)$ & 0.268 \\
\hline Male (\%) & 81.2 & 35.1 & 0.013 \\
\hline Current BMI (kg/m²) & $28.6(24.0 \rrbracket 31.8)$ & $29.7(21.0 \rrbracket 39.1)$ & 0.205 \\
\hline Current BMI $\geq 25.0 \mathrm{~kg} / \mathrm{m}^{2}(\%)$ & 88.8 & 85.7 & 0.643 \\
\hline Current BMI $\geq 27.5 \mathrm{~kg} / \mathrm{m}^{2}(\%)$ & 66.6 & 68.5 & 0.463 \\
\hline Current $\mathrm{BMI} \geq 30.0 \mathrm{~kg} / \mathrm{m}^{2}(\%)$ & 33.3 & 48.5 & 0.477 \\
\hline Current BMI $\geq 35.0$ kg/m² (\%) & 0 & 20.0 & 0.313 \\
\hline Platelet $\left(10^{9} / \mathrm{L}\right)$ & $249(196 \rrbracket 363)$ & $239(104 \rrbracket 437)$ & 0.822 \\
\hline AST (U/L) & $25(14 \rrbracket 33)$ & $24(12 \llbracket 68)$ & 0.869 \\
\hline $\mathrm{ALT}(\mathrm{U} / \mathrm{L})$ & $34(11 \rrbracket 64)$ & $25(11 \otimes 64)$ & 0.323 \\
\hline AST/ALT & $0.8(0.5 \rrbracket 1.2)$ & $0.9(0.6 \bigotimes 1.9)$ & 0.088 \\
\hline \multicolumn{4}{|l|}{ Comorbidity (\%): } \\
\hline Hypertension & 45.4 & 56.7 & 0.731 \\
\hline Hyperlipidemia & 27.2 & 40.5 & 0.499 \\
\hline Diabetes mellitus & 9.0 & 45.9 & 0.035 \\
\hline \multicolumn{4}{|l|}{ Fatty liver } \\
\hline L/S ratio & $1.08(0.64 \llbracket 1.40)$ & $0.97(0.44 \llbracket 1.48)$ & 0.158 \\
\hline L/S ratio < $1.2(\%)$ & 54.5 & 94.6 & 0.004 \\
\hline L/S ratio $\leq 1.0(\%)$ & 36.3 & 51.3 & 0.498 \\
\hline \multicolumn{4}{|l|}{ Liver fibrosis } \\
\hline FIB-4 index & $1.05(0.76 \rrbracket 1.68)$ & $1.15(0.46 \rrbracket 4.93)$ & 0.611 \\
\hline FIB-4 index <1.3 (\%) & 77.7 & 64.7 & 0.693 \\
\hline FIB-4 index <low cutoff point (\%) ${ }^{a}$ & 100 & 67.6 & 0.083 \\
\hline FIB-4 index >2.67 (\%) & 0 & 5.7 & 1.000 \\
\hline FIB-4 index >high cutoff point (\%) ${ }^{b}$ & 0 & 11.7 & 0.563 \\
\hline
\end{tabular}


Data are shown as median (minimum-maximum) and as the percentage. Patients were divided into two groups according to the OPLL type. Fatty liver was defined as an L/S ratio $<1.2$. Severe fatty liver was defined as an L/S ratio $\leq 1.0$. A low risk of advanced liver fibrosis was defined as an FIB-4 index $<1.3$. A high risk of advanced liver fibrosis was defined as an FIB-4 index $>2.67$.

a. low cut-off points are 1.05 for $\leq 49$ years, 1.24 for $50-59$ years, 1.88 for $60-69$ years, and 1.95 for $\geq 70$ years, respectively.

b. high cut-off points are 1.21 for $\leq 49$ years, 1.96 for $50-59$ years, 2.67 for $60-69$ years, and 2.67 for $\geq 70$ years, respectively.

OPLL, ossification of the posterior longitudinal ligament; BMI, body mass index; L/S, liver-to-spleen; FIB-4, fibrosis index based on four factors.

Table 3. Multiple regression analysis for factors associated with the sum of all ossification indices

\begin{tabular}{|c|c|c|c|c|c|}
\hline \multirow[t]{2}{*}{ Independent variables } & \multicolumn{2}{|l|}{ Univariate } & \multicolumn{3}{|c|}{ Multivariate } \\
\hline & $\beta(95 \% \mathrm{Cl})$ & $\begin{array}{l}\mathrm{P}- \\
\text { value }\end{array}$ & $\beta$ & $\begin{array}{l}\text { Standardized } \\
\beta(95 \% \mathrm{Cl})\end{array}$ & $\begin{array}{l}\mathrm{P}- \\
\text { value }\end{array}$ \\
\hline Age (years) & $0.07(-0.45$ to 0.60$)$ & 0.779 & & & \\
\hline $\begin{array}{l}\text { Age of symptom onset } \\
\text { (years) }\end{array}$ & $-0.19(-0.71$ to 0.32$)$ & 0.453 & -0.11 & $-0.06(-0.66$ to 0.42$)$ & 0.668 \\
\hline Sex & $\begin{array}{l}2.94(-6.47 \text { to } \\
12.36)\end{array}$ & 0.523 & & & \\
\hline $\mathrm{BMI}\left(\mathrm{kg} / \mathrm{m}^{2}\right)$ & $0.61(-0.51$ to 1.75$)$ & 0.278 & -0.29 & $-0.07(-1.64$ to 1.05$)$ & 0.659 \\
\hline Hypertension & $\begin{array}{l}5.74(-3.56 \text { to } \\
15.04)\end{array}$ & 0.221 & & & \\
\hline Hyperlipidemia & $\begin{array}{l}3.06(-6.47 \text { to } \\
12.60)\end{array}$ & 0.521 & & & \\
\hline Diabetes mellitus & $\begin{array}{l}5.52(-4.01 \text { to } \\
15.05)\end{array}$ & 0.250 & 3.19 & 0.09 (-7.73 to 14.13$)$ & 0.557 \\
\hline FIB-4 index & 1.78 (-3.16 to 6.72$)$ & 0.471 & 2.21 & $0.13(-2.92$ to 7.34$)$ & 0.388 \\
\hline $\mathrm{L} / \mathrm{S}$ ratio & $\begin{array}{l}-23.98(-41.63 \text { to } \\
-6.32)\end{array}$ & 0.008 & -29.28 & $\begin{array}{l}-0.40(-54.34 \text { to } \\
-4.22)\end{array}$ & 0.023 \\
\hline
\end{tabular}

Table 4. Comparison of clinical characteristics between elderly patients with localized-OPLL and diffuseOPLL (age $\geq 70$ years) 


\begin{tabular}{|c|c|c|}
\hline Variable & $\begin{array}{l}\text { Localized-OPLL } \\
(\mathrm{n}=10)\end{array}$ & $\begin{array}{l}\text { Diffuse-OPLL } \\
(\mathrm{n}=\mathbf{2 5})\end{array}$ \\
\hline Current age (years) & $75(73 \rrbracket 88)$ & $80(70 \otimes 86)$ \\
\hline Age of OPLL symptom onset (years) & $65(50 \otimes 80)$ & $70(20 \otimes 80)$ \\
\hline Age of onset $<50$ years (\%) & 10.0 & 16.0 \\
\hline Male (\%) & 90.0 & 16.7 \\
\hline Current BMI (kg/m²) & $26.3(19.1 \otimes 31.2)$ & $25.4(15.6 \rrbracket 34.7)$ \\
\hline Current BMI $\geq 25.0 \mathrm{~kg} / \mathrm{m}^{2}(\%)$ & 75.0 & 60.0 \\
\hline Current BMI $\geq 27.5 \mathrm{~kg} / \mathrm{m}^{2}(\%)$ & 37.5 & 24.0 \\
\hline Current BMI $\geq 30.0 \mathrm{~kg} / \mathrm{m}^{2}(\%)$ & 25.0 & 12.0 \\
\hline Current BMI $\geq 35.0 \mathrm{~kg} / \mathrm{m}^{2}(\%)$ & 0 & 0 \\
\hline Platelet $\left(10^{9} / \mathrm{L}\right)$ & $218(159 \rrbracket 309)$ & $215(126 \rrbracket 362)$ \\
\hline AST (U/L) & $20(19 \rrbracket 33)$ & $19(12 \varangle 48)$ \\
\hline $\operatorname{ALT}(U / L)$ & $26.4 \pm 17.0$ & $15.6 \pm 10.7$ \\
\hline AST/ALT & $0.9(0.4 \rrbracket 1.6)$ & $1.4(0.8 \llbracket 3.6)$ \\
\hline \multicolumn{3}{|l|}{ Comorbidity (\%): } \\
\hline Myocardial infarction & 10.0 & 0 \\
\hline Angina pectoris & 0 & 8.0 \\
\hline Hypertension & 50.0 & 68.0 \\
\hline Hyperlipidemia & 50.0 & 48.0 \\
\hline Diabetes mellitus & 20.0 & 36.0 \\
\hline Cancer & 20.0 & 20.0 \\
\hline Renal disease & 0 & 0 \\
\hline Gout & 0 & 12.0 \\
\hline Drinking alcohol habits (\%) & 30.0 & 20.0 \\
\hline \multicolumn{3}{|c|}{$\begin{array}{l}\text { Data are shown as mean } \pm \text { standard deviation for normally distributed variables and median } \\
\text { (minimum-maximum) for non-normally distributed variables, and as the percentage. The patients } \\
\text { were divided into two groups according to OPLL type. }\end{array}$} \\
\hline
\end{tabular}


Table 5. Comparison of the severity of fatty liver and liver fibrosis between elderly patients with localizedOPLL and diffuse-OPLL

\begin{tabular}{|c|c|c|c|}
\hline Variable & $\begin{array}{l}\text { Localized-OPLL } \\
(n=10)\end{array}$ & $\begin{array}{l}\text { Diffuse-OPLL } \\
(n=25)\end{array}$ & P-value \\
\hline L/S ratio & $1.16(0.77 \otimes 1.60)$ & $1.22(0.37 ه 1.67)$ & 0.627 \\
\hline L/S ratio <1.2 (\%) & 50.0 & 40.0 & 0.711 \\
\hline L/S ratio $\leq 1.0(\%)$ & 30.0 & 12.0 & 0.321 \\
\hline FIB-4 index & $1.67 \pm 0.37$ & $2.29 \pm 1.08$ & 0.048 \\
\hline FIB-4 index <1.95 (\%) & 80.0 & 44.0 & 0.027 \\
\hline FIB-4 index $>2.67(\%)$ & 0 & 20.0 & 1.000 \\
\hline \multicolumn{4}{|c|}{$\begin{array}{l}\text { Data are shown as mean } \pm \text { standard deviation for normally distributed variables and median } \\
\text { (minimum-maximum) for non-normally distributed variables, and as the percentage. Patients were } \\
\text { divided into two groups according to the OPLL type. Fatty liver was defined as an L/S ratio } \\
<1.2 \text {. Severe fatty liver was defined as an L/S ratio } \leq 1.0 \text {. A low risk of advanced liver fibrosis was } \\
\text { defined as an FIB-4 index }<1.95 \text {. A high risk of advanced liver fibrosis was defined as an FIB-4 index } \\
>2.67 \text {. }\end{array}$} \\
\hline \multicolumn{4}{|c|}{$\begin{array}{l}\text { OPLL, ossification of the posterior longitudinal ligament; L/S, liver-to-spleen; FIB-4, fibrosis index } \\
\text { based on four factors. }\end{array}$} \\
\hline
\end{tabular}

\section{Figures}



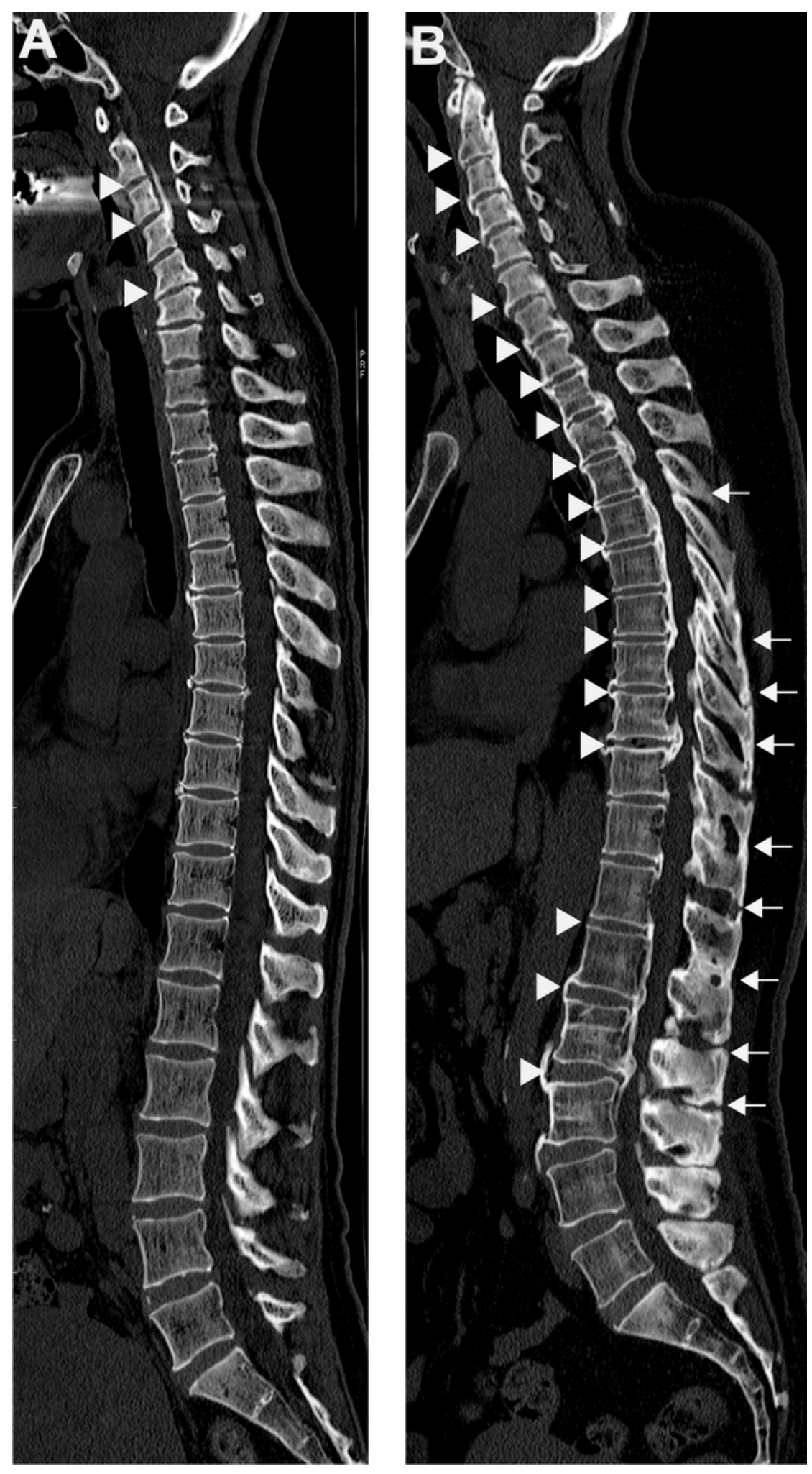

\section{Figure 1}

Sagittal reconstruction CT images of the entire spine in patients with OPLL. (A) A representative case from the localized-OPLL group. A 57-year-old woman without NAFLD (the L/S ratio: 1.41) had OPLL (arrow heads) in the cervical spine. (B) A representative case from the diffuse-OPLL group. A 49-year-old woman with NAFLD (the L/S ratio: 0.94) had multilevel OPLL and OALL of the whole spine (arrow heads) and multilevel OLF and OSIL in the thoracolumbar spine (arrows). NAFLD, non-alcoholic fatty liver 

longitudinal ligament; OLF, ossification of the ligamentum flavum; OSIL, ossification of the supra/interspinous ligaments.

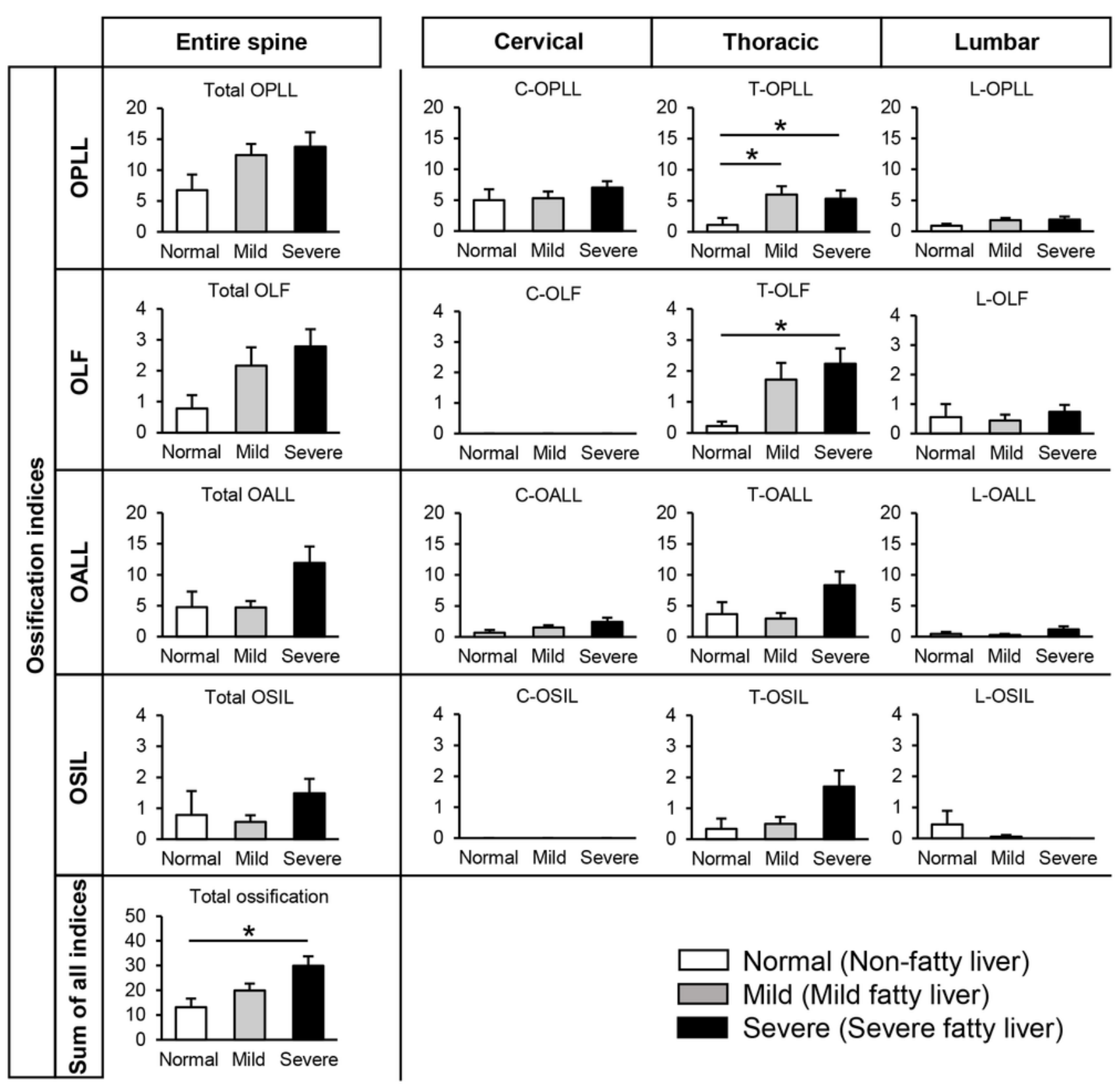

Figure 2

Comparison of the severity of ossification of the spinal ligaments among middle-aged patients with nonfatty liver, mild fatty liver, and severe fatty liver. Bars and error bars indicate the mean and the standard 
error of the mean, respectively. *: $\mathrm{P}<0.05$. C: cervical, $\mathrm{T}$ : thoracic, L: lumbar 